\title{
Do Cadet Force Units need a Dedicated Medical Pack?
}

\author{
Maj JS Nguyen-Van-Tam \\ BMedSci, BM, BS, RAMC(V) \\ Medical Officer \\ Lincolnshire $A C F$ \\ Lecturer in Public Health Medicine \\ Department of Public Health Medicine and Epidemiology, University of Nottingham
}

\author{
Professor RJ Madeley \\ MB, BS, MSc, DM, FFPHM \\ Professor and Head of Department
}

Medical School, Queen's Medical Centre, Nottingham NG7 2UH
Department of Public Health Medicine and Epidemiology, University of Nottingham

SUMMARY: There are over 38,000 army cadets in the United Kingdom of whom about 20,000 attend a two week annual camp each summer. In response to criticisms from the medical staff attached to cadet units about the suitability of the routinely issued medical pack, a national questionnaire survey of all serving Army Cadet Force medical personnel has been performed, along with an analysis of patient attendances at annual camp between 1989 and 1992 in one East Midlands County Force. In particular the appropriateness of the Medical Treatment Pack Training Camp Large as currently issued to cadet units has been examined. The findings suggest that, on its own the pack is unsuitable to treat about $40 \%$ of cadets who attend for medical treatment during annual camp; medica $c$ staff on average rate its suitability for cadets as very low. Moreover, there is objective evidence that most caded units need to obtain extra medical supplies, particularly bronchodilators, modern antibiotics and moderof dressings; many do so via private purchases from civilian sources. The study highlights a situation in urgent need of review.

\section{Introduction}

There are currently 61 county units of the Army Cadet Force (ACF) in the United Kingdom with 38,314 serving cadets (1); about 20,000 of these attend a two week annual camp each year (1). In recent years the routine medical provision for cadet annual camps has been the Medical Treatment Pack Training Camp Large (MTPL) (NATO part no. 6545-99-211-7517). Over some time an appreciable number of adverse individual comments have been made about this pack; collectively these suggest that the medical and nursing personnel attached to cadet units find the current provision unsuitable for meeting the health care needs of army cadets at annual camp. We describe a national survey conducted to quantify objectively any deficiencies in the scale of medical items currently issued to cadet units.

\section{Methods}

\section{Analysis of Treatment Patterns}

In Lincolnshire Army Cadet Force a medical treatment register has been maintained prospectively at each annual camp since 1989. This counts attendances rather than individuals, showing basic patient details (age, sex, company/detachment) and medical information including presenting complaint, diagnoses, treatments and disposai From this register (1200 entries) a random sample of 176 attendances (15\%) between 1st January 1989 and $31 \mathrm{st}$ December 1992 was taken to determine the proportion of problems satisfactorily treated with items solely from the MTPL and the proportion of problems treated with a Prescription Only Medicine (PoM), or by surgical procedure or dressing; further analyses described the proportion of attendances in each of three main diagnostic groups: trauma and orthopaedics, medical and surgical (including gynaecology), and the proportion of attendances related to a chronic medical problem (defined as an illness or condition which had arisen before annual camp).

\section{Questionnaire Survey}

In April 1993, a questionnnaire was sent to each medical officer (MO) currently in post with an ACF unit and to each nursing officer (NO) in post without an MO. The questionnnaire presented a modified inventory of the $\widetilde{N}$ MTPL and asked respondents to rate the importance of $\mathrm{N}$ each item for treating cadets by using a five-point scale $\underset{\mathrm{C}}{ }$ from 'not required' through 'low importance', 'medium importance' and 'high importance' to 'essential'. Similar 
questions were posed about the quantity of each item supplied using a response scale of 'not enough', 'about right', to 'too much'. Respondents were also asked to give overall assessments of the MTPL in terms of its content, quality, and suitability for cadets, using a scale ranging from 0 ('extremely bad') to 10 ('excellent'). A final section asked if other items had been purchased or obtained to supplement the MTPL. The results were analyzed using SPSS-PC (2).

\section{Results}

In the 4 years of the register there were 1202 attendances, giving an average of 300 in each two week camp.

\section{Treatment Patterns and Case-mix}

Of all 176 attendances examined, only $5(2.8 \%)$ required off-camp facilities such as a local hospital. For the 170 attendances where sufficient data were available, $99(58.2 \%)$ were treated solely with items from the MTPL whilst the remainder required additional items or services. A Prescription only Medicine (PoM) was given out in 112 of 173 instances $(64.7 \%$ ), (missing data $=3$ ); however these items were only available in the MTPL on 64 occasions $(57.1 \%)$. Similarly 70 of 173 attendances $(40.5 \%)$ resulted in some form of surgical treatment or dressing but only 33 of these $(47.1 \%)$ could be provided from the MTPL alone.

Of 172 diagnoses made, $88(51.2 \%)$ were traumatic or orthopaedic, $77(44.8 \%)$ medical, and $7(4.1 \%)$ surgical. The MTPL alone was suitable to treat only $53.5 \%, 68.9 \%$ and $0.0 \%$ of these respectively. Fourteen of 176 attendances $(8.0 \%)$ were related to chronic medical conditions such as asthma and seasonal allergic rhinitis; 12 of these $(85.7 \%)$ required a PoM.

\section{Questionnaire Study}

Questionnnaires were sent to $61 \mathrm{ACF}$ headquarters; 2 of these were discovered to be units too small to have an establishment for medical staff, and 1 other shared its annual camp with another unit. A 'nil return' was received from 18 headquarters where there was no $\mathrm{MO}$ or NO in post, leaving 40 units capable of providing information; of these 32 replies were received (from 21 MOs and 11 NOs) representing a response rate of $80.0 \%$. Of the 21 doctors who responded, 15 were from General Practice backgrounds, 3 were trained as Public Health Physicians and 3 were Hospital Consultants. Of the 11 nurses in the study, 3 were based in hospital practice, 3 in Occupational Health, 2 in General Practice and 3 did not specify.

Table 1 depicts how the majority of ACF medical personnel perceived the value of each item supplied in the MTPL in terms of importance and quantity. It can be seen that 10 of 74 items $(13.5 \%)$ were judged by a majority of respondents to be of 'low importance' or 'not required'; 8 of these $(80.0 \%)$, mainly hypnotic drugs and strong analgesics were also judged to be supplied in excessive quantity. Twenty items $(27.0 \%)$ were considered by the majority of respondents to be of only 'medium importance'; 2 of these $(10.0 \%)$ were considered to be over supplied. Of the 46 items $(62.2 \%)$ regarded by the majority as 'highly important' or 'essential', 14 of these 0 (30.4\%) almost exclusively inhaled $\beta_{2}$-agonists, $\ddot{\Rightarrow}$ dressings, bandages, and other non drug items, were judged to be present in insufficient quantity. On average, the MTPL scored 5/10 for its overall content, $7 / 10$ for overall quality, but only $4 / 10$ for its overall suitability for cadet units. Twenty of 28 respondents who gave information $(71.4 \%)$ indicated that their cadet unit $\%$ regularly purchased or obtained supplementary medical items for use at annual camp. Table 2 gives details of these supplementary items by category of drug or item and the number of units which obtained them; these data help to clarify the perceived deficiencies of the MTPL in its current application to cadet units. It is noteworthy that 12 of 28 units $(42.9 \%)$ obtained supplementary respiratory drugs; these almost entirely comprised inhaled $\beta_{2}$-agonists and corticosteroids for use in patients with asthma. Many more of the supplementary items of mentioned were remarkably simple, such as a range of modern dressings, small disposable items, e.g. disposabł gloves and stitch cutters, borderline (non-prescriptiorid substances, e.g. insect repellant and lip salve, an treatment room accessories, e.g. 'sharps' bins; 10 of 28 units $(35.7 \%)$ purchased or obtained tubular suppof bandage. Five of the 21 doctors surveyed $(23.8 \%)$ did nof have access to an National Health Service prescriptio pad (FP10S) in the 1992 camping season.

\section{Discussion}

Before discussing the detailed findings of this study it $\stackrel{\square}{\circ}$ is worth mentioning some of its potential limitations. This $\overrightarrow{\overrightarrow{0}}$ survey was not designed to address any of the 'supply side' issues involved in arranging adequate medical provision for cadet annual camps, and is intended to stimulate debate and further discussions. Nonetheless this is the first time that the views and opinions of ACF medical personnel have been collectively gathered and objectively assessed, making these data unique. Whilst the numbers of respondents are small (in epidemiological terms) a response rate of $80 \%$ is extremely high and ensures that the survey represents the majority view of qualified medical personnel serving with the ACF.

\section{Treatment Patterns and Case-mix.}

The analyses of medical attendances by cadets from Lincolnshire ACF during the period 1989-92 clearly indicate potential inadequacies of the MTPL as applied to the treatment of cadets. Only about $60 \%$ of problems $\sigma$ could be dealt with using the pack alone; in particular, N less than $50 \%$ of wound dressings and surgical treatments could be provided by this means and over $40 \%$ of PoM items had to be obtained from other sources. The analysis

\section{(n)} (1)

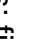


Table 1

Majority opinions about the perceived value of items in the MTPL in terms of importance and quantity as applied to the treatment of cadets.

\begin{tabular}{|c|c|c|c|c|c|}
\hline \multicolumn{6}{|c|}{ Relative Importance } \\
\hline Quantity & low importance or not required & \multicolumn{2}{|c|}{ medium importance } & \multicolumn{2}{|l|}{ high importance or essential } \\
\hline too great & $\begin{array}{l}\text { Atropine sulphate eye drops } \\
\text { Benethamine Penicillin i.m. } \\
\text { injection } \\
\text { Ketamine Hydrochloride i.m. } \\
\text { injection } \\
\text { Lorazepam injection } \\
\text { Nitrazepam tablets } \\
\text { Pentazocine tablets } \\
\text { Temazepam capsules }\end{array}$ & \multicolumn{2}{|c|}{$\begin{array}{l}\text { Senna tablets } \\
\text { Tetracycline tablets }\end{array}$} & \multicolumn{2}{|l|}{ No items } \\
\hline about right & $\begin{array}{l}\text { Clove oil } \\
\text { Zinc Undecanoate cream }\end{array}$ & \multicolumn{2}{|c|}{$\begin{array}{l}\text { Aluminium Hydroxide tablets } \\
\text { Amethocaine Hydrochloride eye drops } \\
\text { Betamethosone Valerate ointment } \\
\text { Benzyl Benzoate application } \\
\text { Cimetidine tablets } \\
\text { Clotrimazole vaginal tablets } \\
\text { Benylin expectorant mixture } \\
\text { Fluorescein Sodium eye drops } \\
\text { Indomethacin capsules } \\
\text { Lignocaine } 2 \% \text { with adrenaline } \\
\text { Magnesium trisilcate tablets } \\
\text { Malathion lotion } \\
\text { Neomycin Sulphate ointment } \\
\text { Polybactrin spray } \\
\text { Sulphacetamide eye ointment } \\
\text { Bandage plaster of paris impregnated } \\
\text { Dressing burn sterile } \\
\text { Wooden tongue depressors }\end{array}$} & ALL OTHER ITEMS IN MTPL & \\
\hline not enough & No items & No items & & $\begin{array}{l}\text { Calamine Lotion } \\
\text { Chloramphenicol eye ointment } \\
\text { Chlorhexidine Gluconate sachets } \\
\text { Paracetamol tablets } \\
\text { Salbutamol inhalers } \\
\text { Adhesive plaster zinc oxide (2 types) } \\
\text { Bandage crepe } \\
\text { Bandage elastic (2 types) } \\
\text { Dressing assortment waterproof } \\
\text { Gauze surgical (sterile) } \\
\text { Basin emesis } \\
\text { Bottle tablet dispensing }\end{array}$ & \\
\hline \multicolumn{3}{|c|}{$\begin{array}{l}\text { of diagnostic categories shows approximately } 50 \% \text { relate } \\
\text { to trauma and orthopaedics and } 45 \% \text { to general medical } \\
\text { problems; it is particularly noteworthy that almost } 10 \% \text { of } \\
\text { all attendances occurred because of chronic underlying } \\
\text { illness, especially asthma and seasonal allergic rhinitis. } \\
\text { These data clearly indicate a case-mix not dissimilar to a } \\
\text { civilian Accident and Emergency department; medical } \\
\text { provision needs to cater for this balance of work. }\end{array}$} & \multirow{2}{*}{\multicolumn{3}{|c|}{$\begin{array}{l}\text { emerges with respect to the undersupply of inhaled } \beta_{2} \\
\text { agonists and corticosteroids and a wider range of } \\
\text { antimicrobial drugs. It must be stressed that in } 1992 \\
\text { almost one quarter of ACF doctors had no means of } \\
\text { prescribing items additional to those contained within the } \\
\text { issued medical pack, except by private prescription. } \\
\text { Besides the lack of sufficient quantities of some drugs, a } \\
\text { clear lack of modern bandages and dressings, antiseptics, } \\
\text { and borderline substances has also been highlighted; with } \\
\text { respect to the latter, it should be borne in mind that during } \\
\text { cadet camps the Medical Incident Room functions as the } \\
\text { focal point for all medical problems including a number } \\
\text { of minor ailments, which would ordinarily have been } \\
\text { dealt with from the contents of a family medicine chest or } \\
\text { bathroom cabinet. In its defence, the MTPL is designed to } \\
\text { sustain about } 500 \text { military personnel for disease and non- }\end{array}$}} \\
\hline $\begin{array}{l}\text { Suitability o } \\
\text { Responde } \\
\text { should be i } \\
\text { supplementa } \\
\text { of units (Ta } \\
\text { variation an } \\
\text { of individu }\end{array}$ & $\begin{array}{l}M T P L \\
\text { views regarding the MTPL } \\
\text { rpreted in conjunction with } \\
\text { tems purchased or obtained by } \\
\text { 2). Accepting that there will } \\
\text { me idiosyncrasy in the prescril } \\
\text { clinicians, a clear theme no }\end{array}$ & $\begin{array}{l}\text { Table 1) } \\
\text { e list of } \\
\text { ver } 70 \% \\
\text { lways be } \\
\text { ng habits } \\
\text { etheless }\end{array}$ & & & \\
\hline
\end{tabular}


Table 2

Supplementary items currently purchased or procured by ACF units

\begin{tabular}{lc}
\hline Category & $\begin{array}{c}\text { Number of cadet } \\
\text { units obtaining items* }\end{array}$ \\
\hline gastrointestinal drugs & 2 \\
cardiovascular drugs & 0 \\
respiratory drugs & \\
$\quad$ (including antihistamines) & $12^{* *}$ \\
central nervous system drugs & $3 * * *$ \\
antimicrobial drugs & 3 \\
endocrine drugs & 0 \\
genitourinary drugs & \\
$\quad$ (including contraceptives) & 1 \\
musculoskeletal drugs & 4 \\
ophthalmic drugs & 1 \\
ENT drugs & 0 \\
dermatological drugs & 7 \\
immunological drugs \& vaccines & 0 \\
dressings & 8 \\
bandages & 3 \\
support bandages (tubigrip etc.) & 10 \\
suture materials & 2 \\
minor disposable items & 4 \\
borderline substances & \\
$\quad$ throat lozenges etc.) & 9 \\
antiseptics & 6 \\
emergency drugs & 2 \\
medical room accessories & \\
$\quad$ (scissors sharps bins etc.) & 4 \\
\hline * one respondent said he purchased "too many items \\
** to remember" & \\
$* * * \quad$ mainly inhaled $\beta_{2}$ agonists and cortiocosteroids \\
$\quad$
\end{tabular}

battle injuries' during the period of a two week training camp; inevitably this intended usage limits its applicability to traumatic and musculoskeletal injuries such as those commonly seen in cadets.

ACF units attending annual camp account for approximately 260,000 person-days per annum. They represent an entirely different population from that which is usually encountered in a typical military training camp. It is therefore not surprising that their health needs are different and that these are poorly met by existing medical packs designed for other purposes. The findings of this report provide objective evidence that the MTPL is inadequate on its own to treat at least $40 \%$ of the medical 3 problems reported at cadet camps, and that dissatisfaction $\mathbb{\complement}$ among ACF medical personnel is generally high. Specifico criticisms of the MTPL relate more to its failure to provide many items which are commonly needed, than tọ? the supply of unwanted items. Many cadet units clearly $\overrightarrow{\overline{\vec{n}}}$ feel obligated to purchase additional items which they regard as necessary.

The detailed findings of this survey have been submitted through the appropriate chain of command to UKLF and MOD Operations and Logistics with a view to 2 the future provision of a more appropriate cadet medicalø pack; so far little progress has been made towards $\vec{\circ}$ achieving this goal. Stocks of the MTPL are nearing exhaustion or expiry, and this presents a considerable $\vec{\omega}$ practical opportunity to improve the existing? arrangements. Medical provision likely to prove adequate for cadet units through the 1990's and beyond musto address the treatment of both medical problems $\vec{A}$ (particularly respiratory disease) and accidents. This $\overrightarrow{ }$ might be partially achieved by combining Primary CareN and Treatment Bay Modules at all future cadet camps, although neither one of these on its own is likely to proveo sufficient. Further flexibility, such as local prescribigg through civilian channels, may still be needed 西c incorporate additional demands for 'inhalers' and othe्ठित 'family practitioner favourites'.

\section{Acknowledgements}

The authors wish to acknowledge financial support this study given by the Ministry of Defence, Directora⿳亠丷⿵冂丶 of Reserve Forces and Cadets (formerly DARC). Practic $\overline{y l}$ advice and support was provided by Brig P I B Stevenson, Secretary East Midlands TAVRA, and Col R J M $\underset{\complement}{\mathbb{Q}}$ Drummond, Deputy Secretary East Midlands TAVRA. $\overrightarrow{\overrightarrow{0}}$ Finally thanks are due to Sue Steel, Janice Gillard and the $\frac{0}{3}$ many Cadet Executive Officers, Medical Officers and Nursing Officers who gave freely of their time to participate.

\section{REFERENCES}

1. Army Cadet Force Association. ACF Statistical Survey. London: ACFA, March 1993.

2. NoRUSIS MJ/SPSS INC. SPSS-PC+V2.0. Base manual. Chicago: SPSS Inc. 1988.

\section{Editor's note:-}

This excellent article refers to the old Medical Treatment Pack Training Camp Large. The Primary Care Module has been radically reorganised and ought to suit the authors' needs. 